\title{
Study of the Translation for Metaphor in Financial English Based on
}

\section{Cognitive Linguistics}

\author{
Zhaoying $\mathrm{Li}^{1, \text { a }}$ \\ ${ }^{1}$ Jilin Business and Technology College130507 \\ aemail,
}

Keywords: Financial English, Metaphor, Translation

\begin{abstract}
With the rapid development of world economy and the booming of China's market, the interflow between countries become increasingly frequent, and market's demand for the talents that have both language ability and financial knowledge become bigger and bigger. Under such international and domestic background, financial English as one communication tool, taking research on how to translate more accurately and how to understand its meaning more thoroughly have important practical significance for people from all walks of life. Metaphor, as one kind of rhetorical device of hiding comparison often appear in financial English, so knowing the use of this technique plays an important role for understanding the financial English. Taking the financial English as the research object, this paper summarizes the current research situation of the translation for metaphor in financial English, besides, according to the analysis of the concluded translation methods and experience by scholars both home and abroad, and also combine with the examples of various financial articles translation, it summarizes the translation techniques for the metaphor part in current financial English translation, how to better apply these skills and several problems that need to be paid attention in the process of translation so that to provide reference value and practical guiding significance for the financial English translation study .
\end{abstract}

\section{Introduction}

Metaphor, the explanation of Baidu encyclopedia is that 'metaphorical interpretation, also known as simple metaphor. Skillfully use metaphor, which plays an important role for the vividness, concision and emphasis etc. techniques of expression, and it is more flexible and visual than simile.'For a long time, metaphor is simply regarded as a rhetorical device and it is just a kind of phenomenon of language usage. With the deepening of research on language by scholars, the theoretical system of metaphor constantly enriches and expands. In the year of 1980, the book Metaphors We Live By by the coauthor Lakoff and Johnson,the founder of cognitive linguistics puts forward that the cognitive language concept ofmetaphor marks the rise of metaphor from pure language category to the category of thinking cognition. They think that metaphor is everywhere, which not only exists in language, but also exist in people's thinking and behavior.

\section{Application of Metaphor in Financial English}

Lakoff and Johnson mentioned in their book Metaphors We Live By the theory of conceptual metaphor and the putting forward of this revolutionary ideas speeds up the development of cognitive linguistics. Lakoff divided conceptual metaphors into three parts: orientational metaphor, ontological metaphor 
(entity metaphor) and structural metaphor.

Orientational Metaphor. Up-down, inside-outside, front-back, deep-shallow, center-edge etc. such basic spatial relationship form by human's perception on orientations, which is the basic concept of our daily life. When we expose to an abstract concept, we will naturally connect these abstract concepts to concrete spatial orientation, and then the so-called orientational metaphor forms. The abstract concepts can refer to mood, thought, quality, social status, right or wrong, time etc., such as 'up' and 'down' explaining the orientational metaphor, the Chinese translation of 'up' is . Men struggle upwards and water flows downwards, so in our common sense, 'high' and 'up' both have the concept related to the 'good', conversely 'down' has some negative connotations. Applying the orientational concept into financial English is not human's subjective thought of compulsory connection, but forms along with the growth of the human experience and the perception on their own and the space environment relationship. Not only one pair of space position antonyms 'up' and 'down' are used in financial English, people , but a variety of words are used, such as, 'rise in price', 'All stock prices have jumped up this month'

More examples:

(1) During the bull market in property, with price rising fast, auctions became increasingly popular.

(2) The news hit sentiment like a bucket of cold water; on October $17^{\text {th }}$ the stockmarket slumped by more than $9 \%$ in a few minutes, leading to a one-hour trading suspension.

(3) The number of these entities has soared in recent years, and they now account for about half of the income earned by American business.

(4) The Treasury calculates that getting rid of all existing allowances would broaden the tax base enough to allow the rate to be cut to $27 \%$.

Ontological Metaphor (Entity Metaphor). Ontological metaphor refers to the use of an entity word to represent an abstract concept. As the cognitive experience on the spatial position of the human body can produce orientational metaphor, our experience of objects (especially our bodies) provide extremely wide entity metaphor basis, that is, we can regard the events, activities, emotions, thoughts, etc. as entities or materials (Lakoff\&Johnson, 1980:25). Such as 'invisible hand', the hand is mainly used to grab and hold things, thus it has the meaning of 'master'. Under the normal circumstances, the market will maintain its healthy operation in its intrinsic mechanism. Among that, the mainly basis are the economic man's rational principle in the market economic activities and the rational choices under the domination of economic man's rational principle. These choices gradually form the price mechanism, supply and demand mechanism and competition mechanism in the market economy. These mechanisms like an invisible hand dominate everyone in the unseen world and consciously operate in accordance with the law of market.

More examples:

(1) Under the Investment Company Act of 1940, closed-end funds are capitalized only once. They make an initial public offering (IPO), and then their shares are traded on the secondary market, just like any corporate stock. The number of shares is fixed at the IPO; closed-end funds cannot issue more shares. In fact, many closed-end funds become leveraged to raise more funds without issuing more shares.

(2) Economists view the world a being the outcome of the "invisible hand", that is, a world where private decisions are unknowingly guided by prices to allocate resources efficiently.

(3) The first two villains were bubbles and leverage. We now turn our attention to the other five members of the hall of shame, beginning with the abysmal performance of the nation's financial regulatory agencies.

(4) Here's what you have to do to insure financial security. 
(5) The thought of the economist was confused, like the bats above her, flying this way and that.

\section{Structural Metaphor}

Structural metaphor is the most widely used metaphor, which is not only a kind of figures of speech in the traditional sense, but also a way of thinking and cognition for human to understand the world around them and cognize new things. It uses one conceptual structure to construct another kind of concept, and its mapping belongs to the partial mapping, besides, it makes superposition of the two concepts' function, and apply the vocabulary describing one concept into describing another concept. In financial English, structural metaphor is a good way to avoid the national culture, military and historical differences and covers up the connection of the generation of financial thought and policy with the national economy and political context, such as, 'Business is war', so all that vocabularies that used to describe the battlefield, such as 'fierce competition', 'cruelty' etc. can be used to describe the market. 'Time is money.', the concept of money, in people's mind has the characteristics of 'precious', 'easy to lose', etc. Use the known specific concept 'money' to cognitive abstract concept 'time', then when we describe the 'time', we can combine with the the verbs 'save' 'waste' 'spend' etc., which is not only vivid and image, but also can convey the characteristics that time is very precious, not easy to come, and easy to be consumed.

More examples:

(1) The market is telling you that you are using your energies and resources in doing something it doesn't want you to do.

(2) A decade ago, many observers speculated that load funds would become obsolete and no-load funds would dominate because of the investor's aversion to a sales charge.

(3)As a result, banks are hoarding their capital rather than lending it in the money markets.

In the economic field, in addition to Lakoff's typical classification method, there are also many other economists use the concepts in life to take other classifications of the metaphors in economic field, such as, the classifications of animal metaphors, plant metaphors, human metaphors, building metaphor, war metaphor etc., and no more introduction about that will be taken in this paper.

\section{Problems Analysis of Metaphor Translation}

Ignore Metaphor Complexity. It is mentioned above that, metaphor is no longer simply language rhetoric, but is the category of closely associating with human thinking and cognition, so when translate the metaphors, we must know that people with different languages and under different cultural backgrounds have different thinking and cognition, which is the basis of translation. In addition, on the basis of solidly grasping the languages of both sides, the translators should spend energy and attention on the crossover and interaction of the two cognitive fields, which just is the complexity of metaphor translation and it is cannot be ignored. Learning financial English is not only remembering the one-to-one English and Chinese vocabularies, which is effective in the primary stage, however, in the phase of ascension, more flexible comprehension memory is needed and we should rely on background knowledge and experience knowledge to activate and express the knowledge carried by the vocabularies.

Acception or Rejection of Metaphorical Objects. Structurally, metaphorical object can be divided into metaphorical object, connotation and noumenon three parts.Although the connotation is hidden in the metaphorical expression, the information transferred by connotation is the key of metaphor, so it is necessary to pay more attention to how to explain the connotation when we translate metaphor. The famous translator Newmark has pointed out that metaphor translation is the epitome of all language 
translation, because the metaphor translation presents multiple choices to translators. They can transfer its meaning or reshape its phenomenon, or modify it, or make a perfect combination of its phenomenon. The acception or rejection is the difficulty and emphasis of metaphorical object, and it can be summed up in three basic translation methods: retain metaphorical objects, change metaphorical objects and abandon metaphorical objects.

\section{Retain Metaphorical Objects}

Although different regions, different races or different cultures will lead to people's cognitive differences, due to the same human physiological structure and psychological basis, the experience that different ethnic groups gained facing the same outside world have a lot of similarities, so many same or similar metaphorical expressions will appear in different languages.In that case, we should try to retain or reproduce the metaphorical objects of original metaphors,so that we can ensure that the readers can feel the same cognition with the original author.

\section{Example:}

The collapse of the housing bubble, which peaked in the U.S. in 2006, caused the values of securities tied to real estate pricing to plumment thereafter, damaging financial institutions globally.

In this paraphrase, the mentioned structural metaphor in preceding part is used, use the fragile image of bubble to describe the inveracious increase of real estate price, and that price is far more than its real value. 'housing bubble' is translated into 'real estate bubbles', which is one literal translation method, and it can be easily accepted by readers and it can also make the readers immediately get the author's emotion for the real estate price change.

\section{B Change Metaphorical Objects}

When the original metaphorical objects, in the target language culture, cannot make the readers have the same or similar associations and feelings, then it is necessary for the translator to take flexible adaptation. Use the metaphorical objects of same or similar characteristics in target language culture to replace the metaphorical objects in original text so that to make the readers, the translator and the author have the same feelings.

Example:

Cash cows require little investment and generate cash that can be used to invest in other business units.

C Abandon Metaphorical Objects

When retain the metaphorical objects can't make the reader be easy to understand the original text, and the translator also cannot find the suitable replacement for metaphors, the translator can choose the strategy of abandoning the metaphor in original text.

Example:

One possible remedy that may be discussed at the G-7 meeting is for governments to guarantee lending between banks.

The 'remedy' means 'therapeutic method', and in this sentence, it means government's 'rescue measures'.

\section{Conclusion}

Language is the carrier of culture, and in this economy-developed modern society, the application of language and the importance of communication are all important.Metaphor is ubiquitous, so there are a lot of metaphor phenomena in finance discourses, and in the process of translating financial English 
metaphor phenomenon,the key lies in the correct understanding of the original texts and the accurate expressing of the original meaning. For the aspect of understanding, the bigger general English and financial English vocabulary quantity the translators have, the greater language analysis ability will be,and the richer knowledge of economic and financial, cultural, political etc., the better grasping of financial English characteristics and the more thoroughly understanding of the original language.

Intuition and imagination precede concept and reason and they are the foundation of knowledge.Previous English teaching is mainly taken in the levels of concept and intellect and it basically ignores the function of intuition and imagination.In this paper, the analysis of metaphor meaning of financial terms is the comprehension process of language, which has the function of visualization mapping for the financial knowledge in terms.In addition, the meticulous attitude, rigorous wording and modest and remorseless efforts are the key in the advancing process of translation ability.

\section{References}

[1] Fengshi,Acception or Rejection Strategies of Metaphorical Objects Images of Financial English Metaphor Under the Concept of Equivalence Theory[J].Journal of Liaoning Institute of Science and Technology ,2014,16(1):46-49

[2] Yubin Wen, Analysis of Poetry Conceptual Metaphors Translation from the Field of Vision of Cognitive Linguistics As Well As the Advantages and Disadvantages of the Two Versions of A Dream in Red Mansions--Chrysanthemum Chant[J].Journal of Taiyuan City Vocational and Technical College ,2009(1):160-162

[3] Zhangnan,Should the Economy and Trade Translators Pay More Attention to 'English' or 'Business'?[J].scientific and technological information,2014(2):80-80

[4] Shaoqun Li, Creativity and Operation Mechanism of Structural Metaphor in the form of 'Name-1+Name -2'[J].Academic Communication,2007,10:035

[5] Shaoqun Li, Research on the Structural Memes in the Form of 'Name-1+Name -2' of Contemporary Chinese Language[J].Journal of Shanxi Normal University:Social Sciences,2011,38(6):128-131 